\section{Gategory}

Metal-Mediated

Synthesis

\section{Key words}

nickel

cyclization

zinc

\title{
Nickel-Catalyzed Intramolecular Cyclization of Dihaloalkanes
}<smiles>[R][Y10]([H])C([X])[R]</smiles>

$\mathrm{m}, \mathrm{n}=0-2$

$\mathrm{M}=\mathrm{N}, \mathrm{CH}$

$\mathrm{R}^{1}, \mathrm{R}^{2}=\mathrm{H}$, Alk, $\mathrm{Ar}$

$\mathrm{X}=\mathrm{I}, \mathrm{Br}, \mathrm{Cl}$

Selected examples:
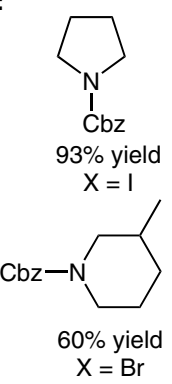

Proposed mechanistic pathways:

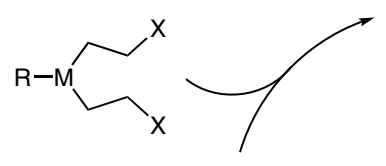

$\mathrm{Ni}^{0}$

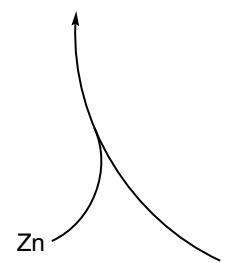

$\mathrm{Nil}_{2}(10 \mathrm{~mol} \%)$ $\underset{\text { 2,2'-bipyridine (10 mol\%) }}{\longrightarrow}$

Zn (3 equiv)

DMA, $25^{\circ} \mathrm{C}$

$\mathrm{Ph}$
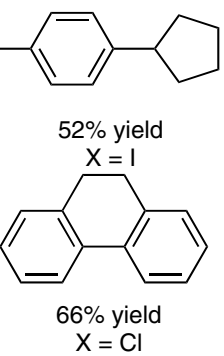

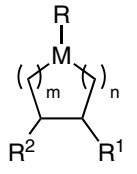

$R^{2} \quad R^{1}$
Significance: The authors have developed an intramolecular cyclization of nitrogen- and carbontethered dihaloalkanes. The protocol is especially effective for five-membered rings and only moderately for six-membered rings. The reactions were performed under mild reactions conditions.

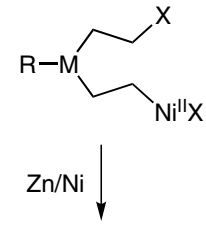<smiles>[X][M]CCC([R])CC</smiles><smiles>[X]CC(C)N([R])CCN</smiles>

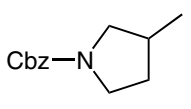

$61 \%$ yield

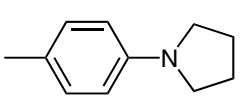

$50 \%$ yield $\mathrm{X}=\mathrm{Br}$

$\mathrm{Ni}^{\mathrm{l}}$

Comment: The coupling involving secondary alkyl halides appears to be more efficient than the cyclization of primary/primary alkyl dihalides. Interestingly, the construction of a seven-membered ring is less efficient. Side-reactions are intermolecular oligomerization and hydrodehalogenation of the substrate. 